\title{
“ERa Uma Vez...” ConsideraÇões Psicanalíticas Sobre A DEFICIÊNCIA E Os Contos De FADAS
}

\author{
Débora Ferreira Bossa ${ }^{1}$ \\ Anamaria Silva Neves ${ }^{2}$
}

\section{Resumo}

Este estudo considera os conhecimentos produzidos pela psicanálise sobre os enigmas e conteúdos inconscientes presentes nos contos de fadas, em diálogo com os conceitos sobre o corpo da deficiência. Foi realizada a leitura e interpretação de três contos de fadas "A mulher que teve a criança trocada", "Riquete do Topete" e "O patinho feio", relacionando a vivência dos personagens com as fantasias que perpassam o corpo da deficiência. Conclui-se que as narrativas apresentaram movimentos de rejeição, mecanismos compensatórios e expulsão para lidar com as angústias e os estranhamentos que o corpo da deficiência mobiliza.

PALAVRAS-CHAVE: contos de fadas; clínica; deficiência; infância; psicanálise

\footnotetext{
${ }^{1}$ Psicóloga pelo Instituto de Psicologia da Universidade Federal de Uberlândia, UFU. Mestre em Psicanálise e Cultura Programa de Pós-Graduação em Psicologia Aplicada, UFU. Endereço para correspondência: Rua Senador Salgado Filho, 727. Tabajaras. CEP: 38400-236. Uberlândia - MG, Brasil. Endereço eletrônico: deborabossa@gmail.com.

${ }^{2}$ Docente Associado II do Instituto de Psicologia da Universidade Federal de Uberlândia - graduação e pós-graduação strictu sensu. Endereço para correspondência: Av. Maranhão, s/n. Bloco 2C. Campus Umuarama. CEP: 38400-902. Uberlândia - MG, Brasil. Endereço eletrônico: anamaria@umuarama.ufu.br
} 
"Era Uma Vez..." Considerações Psicanalíticas Sobre A Deficiência E Os Contos De Fadas

\section{INTRODUÇÃO}

Atualmente, a deficiência pode ser compreendida a partir de duas ênfases: uma que diz respeito à tentativa de normalização do corpo, e outra que reconhece as barreiras sociais como desigualdade. A primeira se pauta no modelo biomédico em que se espera determinado padrão de funcionamento orgânico, mantendo o preceito moral de produtividade e adequação às normas sociais, atenuando os efeitos da anormalidade. E a segunda ênfase, reconhece a deficiência enquanto diversidade da espécie humana, cujo corpo vivencia a opressão de uma sociedade não inclusiva e promotora de desigualdade ao ignorar as várias modalidades de impedimento dos corpos. Para além do comprometimento ou lesões do corpo, o conceito de deficiência estabelece relações de desigualdade em ambientes que perpetuam obstáculos (DINIZ; BARBOSA; SANTOS, 2009).

No contexto da reformulação do conceito de deficiência, para além da perspectiva biomédica, e na consideração da dimensão social, ocorreu a assinatura da Convenção Internacional sobre os Direitos das Pessoas com Deficiência e seu Protocolo Facultativo, em 30 de março de 2007, na cidade de Nova lorque. No Brasil a edição da Convenção sobre os Direitos das Pessoas com Deficiência e seu Protocolo Facultativo, recebeu aprovação e reconhecimento da Secretaria Especial dos Direitos Humanos e Coordenadoria Nacional para Integração da Pessoa Portadora de Deficiência, em documento oficial de setembro de 2007. A Convenção Sobre os Direitos da Pessoa com Deficiência, por meio do Decreto Legislativo n 186 de 09 de julho de 2008, reconheceu a deficiência enquanto um fenômeno que não apresenta estruturação conceitual constante, uma vez que há a consideração do constante processo de evolução social, necessitando ser atualizado a cada momento histórico.

A Convenção sobre os Direitos das Pessoas com Deficiência (BRASIL, 2012) tem como propósito promover e assegurar o exercício pleno e equitativo dos direitos humanos e liberdade fundamentais a todas as pessoas com deficiência. E, considera que as pessoas com deficiência têm como especificidade impedimentos de natureza física, mental, intelectual ou sensorial, cujas barreiras sociais podem obstruir sua participação efetiva na sociedade, estando em condição de desigualdade com as demais pessoas. As políticas públicas estão voltadas para a inclusão social, evidenciando a necessidade de eliminação das barreiras sociais, ideacionais ou 
delimitadoras do ambiente. Nesse sentido, é possível considerar que a compreensão atual sobre a deficiência está relacionada à diversidade da espécie, sendo necessárias mudanças políticas e estruturais na sociedade para acolher as variedades do corpo e suas diversas necessidades. Ao buscar suprimir as barreiras sociais que inviabilizam a ocupação do espaço público do corpo com deficiência, é colocada ênfase na descaracterização do corpo enquanto funcionalidade que visa atender a um ideal estético.

É importante reconhecer que o atual conceito de deficiência é decorrente de extensa construção histórica e social. A deficiência nasce com o ser humano, nunca destituída da espécie, caminhou por longa trajetória, e sofreu inúmeras formas de apreensão e trato. Em algumas sociedades as pessoas com deficiência foram tratadas como divindades, em outras como encarnação do mal, passando por diferentes modos de tratamento, desde glorificação até punições por açoites e morte. Frente ao processo histórico pelo qual a deficiência caminhou, Jerusalinsky (2007) aponta algumas modalidades de apreensão da deficiência: os gregos no Taigeto matavam as pessoas com deficiência; a sociedade egípcia as endeusavam; na Idade Média era comum indicá-las como amaldiçoadas; Lutero empregou a concepção de encarnação do demônio; as ideologias de inspiração nazista consideravam a deficiência como característica de uma raça inferior; até que nos tempos atuais o trato da deficiência visa a reeducação e inserção social.

Foucault (2002), em sua obra "Os Anormais", apresenta várias modalidades de expiação e punição em que a pessoa com deficiência foi submetida entre os séculos XVIII e XIX, pois a condição de estranheza se aproximava ao caráter demoníaco. Os "anormais" elencavam a loucura, o incesto, os crimes violentos e os "monstruosos", cujo destino remetia a duas formas de punição: isolamento, castigos e maus-tratos; e outro, que os condenavam à morte. O termo "monstros" ou "monstruosos" designava as pessoas com deficiência física, caracterizadas pela falta ou excessos de membros no corpo, como os siameses e as pessoas com membros múltiplos.

Nesse sentindo, é possível perceber que a cultura incide sobre o corpo da pessoa com deficiência, apontando sua forma de trato e reconhecimento. Aranha (1995) esclarece que os discursos de inclusão social surgiram a partir do século XX, como consequência da inserção do capitalismo com interesse em aumentar a produção e eficiência dos cidadãos. Os programas de reabilitação surgiram nos Estados Unidos como proposta de reabilitar os soldados egressos da Segunda

145 Psicanálise \& Barroco em revista | v.17, n. 01 | julho de 2019 
"Era Uma Vez..." Considerações Psicanalíticas Sobre A Deficiência E Os Contos De Fadas

Guerra, visando à recuperação, e reinserção no mercado de trabalho. As iniciativas de reabilitação buscavam, dessa forma, normalizar o corpo a partir da superação da deficiência. Diante disso, pode-se compreender que a deficiência passou por longa trajetória de reconhecimento, ocupando diferentes lugares, desde o isolamento até as recentes propostas de inclusão.

A psicanálise também é solicitada a compreender as condições subjetivas e sociais que incidem sobre a deficiência, considerando suas implicações ao sujeito. Escobar, (2012), argumenta que a psicanálise é convocada a debater sobre a deficiência, considerando a dimensão do sujeito, frente ao reconhecimento da constituição psíquica, bem como aborda o corpo para além do comprometimento físico, ou seja, como um organismo transpassado pelo desejo.

A princípio, a psicanálise não se aplicava ao tratamento da pessoa com deficiência, pois se pautava na concepção de que era necessária certa capacidade de abstração para se submeter à análise, uma vez que esse processo se baseava nas formações de estruturas metafóricas e abstratas. Como mostra Brauer (1998), a deficiência foi incluída no processo psicanalítico a partir dos estudos iniciados por Mannoni, na década de 1960, que reconheceu a presença das estruturas psíquicas da psicanálise (neurose, psicose, perversão) não distintas para a pessoa com deficiência, além de compreender que o tratamento da pessoa com deficiência exige aprimoramento da estratégia clínica (BRAUER, 1998).

Enquanto objeto de estudo, a deficiência pode ser reencontrada a partir da leitura dos contos de fadas, considerando as representações inconscientes e movimentações psíquicas tanto nos personagens que vivenciam conflitos postos pela imagem de seus corpos, quanto às ressignificações familiares e sociais que a presença da deficiência mobiliza.

Ao reconhecer os conteúdos inconscientes desvelados por Bettelheim (1979) em "A psicanálise dos contos de fadas", este estudo buscou reconhecer as representações psíquicas e os sofrimentos vivenciados pelos personagens dos contos "A mulher que teve a criança trocada" (GRIMM; GRIMM, 2012), "Riquete do Topete" (PERRAULT, 1997) e "Patinho feio" (ANDERSEN, 2013). Esses contos foram selecionados por terem como ponto em comum o relato dos personagens sobre os conflitos frente o efeito da imagem antecipada do outro sobre o sujeito, cuja forma física difere daquilo que é esperado enquanto normalidade. Os enredos dos contos selecionados foram compreendidos a partir do conhecimento construído pela 
psicanálise, versando sobre os conflitos e movimentos psíquicos apresentados mediante o encontro da deficiência na família e na sociedade, de modo a relacionar a imagem do corpo com os possíveis efeitos causados na subjetividade do sujeito, que porta alguma forma de deficiência.

\section{A Psicanálise E Os Contos De Fadas}

Desde os primórdios da História é possível ter evidências de tentativas humanas para desvendar os mistérios da natureza e das relações, como forma de ultrapassar os limites impostos por sua própria condição. A literatura é uma forma de expressão que visa lidar com a necessidade de saber e dominar a vida. Fábulas, apólogos, parábolas, contos, mitos, lendas, sagas, dentre outros, são exemplos do extenso material narrativo fecundo na humanidade, que guardam determinado saber fundamental. As narrativas, de modo direto ou indireto, simbólico ou realista, atentamse para trazer aspectos comuns aos homens, sobre a vida e formas de como vivê-la. Dessa forma, as narrativas versam sobre a ambivalência da condição humana, que pode se relacionar ou dialogar diretamente com os deuses, ao mesmo tempo em que se mostra limitada aos próprios homens e suas incompreensões sobre as adversidades da vida e do mundo (COELHO, 1987).

O enredo dos contos de fadas pode apresentar as fadas como personagens presentes ou não, além de reis, rainhas, príncipes, princesas, gênios, bruxas, gigantes, anões, objetos mágicos, dentre outros. Os contos de fadas são, caracteristicamente, reconhecidos pelo eixo narrativo composto por uma problemática existencial, que alude a busca de uma realização interior profunda, seja no nível da dimensão da existência singular ou social, além de portarem a sabedoria da palavra e da paixão amorosa para a preservação ou a destruição da vida (COELHO, 1987). Bettelheim (1979) aponta que os detalhes menos significativos são excluídos e os personagens são mais típicos do que únicos, o bem e o mal recebem forma, corpo e ação, cuja dualidade representa o problema moral do conto, convocando o leitor ao conflito e à resolução.

Bettelheim (1979) apresenta nas páginas iniciais de sua obra "A psicanálise dos contos de fadas" a citação do poeta alemão Schiller que se aproxima do percurso teórico desenvolvido na referida obra: "Há maior significado profundo nos contos de fadas que me contaram na infância do que na verdade a vida ensina" (The Piccolomini, III, 4, citado por BETTELHEIM, 1979, p. 14). O autor considera, a partir da citação,

147 Psicanálise \& Barroco em revista | v.17, n. 01 | julho de 2019 
"Era Uma Vez..." Considerações Psicanalíticas Sobre A Deficiência E Os Contos De Fadas

que os contos de fadas dialogam com a imaginação e os conflitos humanos ao representar emoções e aspectos do desenvolvimento intelectual, além de movimentar ansiedades e aspirações, reconhecer dificuldades e sugerir soluções para os problemas que perturbam os personagens.

Nesse sentido, os contos de fadas auxiliam a criança a lidar com o mundo desordenado, sugerindo pistas para compreender sua complexidade, isso porque o dilema existencial é apresentado de forma breve e categórica. Os enredos e seus enigmas interessam crianças e adultos, de modo que as compreensões e os elementos capturados dependem de cada sujeito. Assim, uma mesma pessoa pode ler a mesma obra em distintos momentos de sua vida, e reconhecer nessas leituras diferentes conflitos, tramas e emoções que anteriormente pareciam mais ou menos importantes. Os significados apreendidos dependem, portanto, do interesse dos leitores e necessidades situacionais, oportunizando a ampliação de significados já conhecidos para substituí-los por novos (BETTELHEIM, 1979).

Mannoni, (1995), menciona que os contos trazem a sutileza de apresentar uma imagem que logo em seguida pode ser esquecida, mas deixa um resquício no corpo. A narrativa oferece vida à cena que desaparece no momento em que é representada. Esse movimento pode ser percebido nas situações em que a criança vivencia intensamente o enredo dos contos. Na escuta analítica, a criança assume um ou mais personagens do conto, depositando o agir sobre seu próprio corpo, o enredo oferece elementos de identificação para o simulacro de suas emoções e pensamentos. Os contos podem ser portadores de um segredo terrível e medonho, de modo que algo percebido como assustador se refere ao que não foi retirado pela amnésia infantil. 0 terror, a crueldade ou a violência, produzidos a partir dos contos podem constituir para a criança, ou em seu corpo, um acontecimento próximo ao sacrifício.

Bettelheim, (1979), esclarece que a partir da psicanálise, os contos transmitem informações aos sistemas consciente, pré-consciente e inconsciente, abordando os problemas universais humanos. As histórias que preocupam o pensamento da criança dizem respeito ao Eu em formação, assim como dialogam com conflitos inconscientes. O desenvolvimento das histórias valida e oferece corpo às pressões do Isso, e mostram os percursos para satisfazê-las, seguindo as requisições do Eu e do Supereu.

Schneider e Torossian (2009) reconhecem que, na prática clínica com crianças, os contos de fadas podem ser usados como forma de expressão e simbolização do 
sofrimento. As autoras observam que desde a origem os contos têm função terapêutica, o que explica a permanência e transmissão transgeracional ao longo dos séculos, e relembram que os contos foram utilizados na medicina hindu como método para estimular a meditação para pacientes com transtornos mentais. Para a clínica psicanalítica, os contos têm sido utilizados como recursos que favorecem a introspecção e a projeção, uma vez que, permite, pelas vivencias dos personagens, atualizar uma realidade na qual a criança se reconhece.

\section{A Deficiência Nos Contos De Fadas}

Charles Perrault (França, 1628 - 1703), os irmãos Jacob Grimm (Alemanha, 1785 - 1863) e Wilhelm Grimm (Alemanha, 1786 - 1859), e Hans Christian Andersen (Dinamarca, 1805 - 1875) construíram grande parte do legado literário conhecido atualmente sobre os contos de fadas. Os contos eram difundidos na cultura através da comunicação oral de suas regiões e épocas, e esses autores transcreveram as histórias para a literatura a partir da linguagem popular.

Resgatando os contos "A mulher que teve a criança trocada" (GRIMM; GRIMM, 2012), "Riquete do Topete" (PERRAULT, 1997) e "Patinho feio (ANDERSEN, 2013), discute-se sobre a deficiência como um fenômeno que provoca desdobramentos psíquicos no sujeito e os efeitos impostos pela sociedade.

O conto "A mulher que teve a criança trocada" (GRIMM; GRIMM, 2012) narra que gnomos colocaram uma criança "aberração" no berço e levaram embora a criança "normal" que ali estava previamente. Para resolver o problema, a mulher pediu a ajuda de uma vizinha que sugeriu um desafio: a mulher deveria ferver pequenas porções de água em cascas de ovos, e colocar a criança "aberração" junto ao forno para presenciar o evento. Isso faria com que ela gargalhasse e, assim, os gnomos a resgatariam, trazendo de volta a "verdadeira criança". Enquanto a mulher preparava as cascas de ovo, a criança "aberração" falou: "Sou mais velho que a floresta do Reno, mas nunca vi alguém cozinhar em casca de ovo!" (GRIMM; GRIMM, 2012, vol. II, p. 199). A criança começou a gargalhar e os gnomos colocaram a criança verdadeira junto ao fogão e levaram a "aberração" embora.

A criança do conto é indicada como tendo uma cabeça gigante e olhos inexpressivos, além de recusar a alimentação. O sentimento de desconhecimento é despertado tanto na mulher quanto na criança. A criança "aberração" anuncia ser mais velha que a floresta do Reno, considerando que a deficiência é uma característica da

149 Psicanálise \& Barroco em revista | v.17, n. 01 | julho de 2019 
"Era Uma Vez..." Considerações Psicanalíticas Sobre A Deficiência E Os Contos De Fadas

espécie humana, não podendo ser destituída de sua existência. Apesar de ser uma condição intrínseca da espécie humana, a deficiência passou, historicamente, por processos de exclusão.

Andrade e Sólera, (2006), reconhecem que o encontro com a deficiência emerge a marca da debilidade e da impotência, características forçosamente excluídas da imagem que o sujeito reconhece, ou constrói de si. A deficiência é negada, pois, oferece uma imagem incômoda e não correspondente àquela construída a partir do eu ideal, associada à perfeição narcísica e, por isso, é produtora de angústia.

A mulher do conto se deparou com a estranheza da criança e, não se reconhecendo no corpo desta, inviabiliza a instauração da posição materna, sendo nomeada como mulher e não como mãe durante o conto. Ao olhar para a criança, a mulher não reconhece a maternidade, pois, primeiramente, não se reconhece na criança, o que exclui a filiação.

O nascimento de uma criança com deficiência na família pode ser pressentido como uma catástrofe ou heroísmo a depender da colocação dela no desejo dos pais, promovendo reconfigurações na relação familiar. Brauer, (1998), esclarece que a deficiência ocupa um espaço especial no imaginário familiar e social e pode ter diversas representações. A presença da deficiência na família pode simbolizar o lugar de depósito ou a corporificação de um problema, de uma maldição, culpa ou castigo.

Jerusalinsky, (2007), aponta que a mãe da criança com deficiência se percebe enquanto objeto narcísico quebrado, não sendo possível oferecer uma identificação fixa, demandando o encobrimento de seu desejo. A criança, assim, é colocada a representar desde a morte até a imagem da criança que não nasceu, um gênio esperado, mas impossível. A descontinuidade é experimentada pela criança na medida em que a mãe oferece essas imagens fragmentadas.

Lacan, (1949 [1998]), considerou o estádio do espelho como o momento de reconhecimento e constituição do psiquismo, permeado pela fascinação à imagem oferecida pelo olhar materno. No processo de especularização, que compõe o estádio do espelho, a mãe recobre com o olhar o corpo do bebê, cuja identificação imaginária com o Outro (agente materno) coloca-o na condição de perceber-se enquanto totalidade.

No trato com a criança, a mãe (ou aquele que ocupa esse lugar) olha a si mesma no corpo da criança, processo fundamental para a constituição do sujeito e 
para a inscrição da criança na identificação com a alteridade. A mãe da criança com deficiência pode não conseguir se reconhecer no corpo da criança, ou se identificar com estranheza a esta, podendo não oferecer a ilusão de totalidade, e sim a imagem de corpo fragmentado, fraturado pela deficiência.

É a partir desse processo de especularização que a mãe se dispõe psiquicamente para oferecer os cuidados à criança. E, nessa condição de ruptura com a continuidade do corpo da mãe no corpo da criança que há o risco de a mãe colocar a si mesma no lugar de dependência e debilidade, isso porque não se reconhecendo em tal função delega à equipe de saúde, e outros profissionais, a condição de maternar seu bebê. Essa situação declara a destituição da mãe de seu lugar simbólico para a criança, que a deixa abandonada nos aspectos afetivos e psíquicos (BRAUER, 1998).

Freud, (1914), esclarece que o narcisismo primário é oferecido pelas figuras parentais à criança de modo que se torna herdeira dos ideais não realizados pelos primeiros, bem como reivindicam direitos e privilégios aos quais foram obrigados a renunciar. A criança, por sua vez, aparece na perspectiva dos pais como depósito das melhores expectativas e cumprimento dos desejos irrealizados, como se o desejo de imortalidade pudesse instaurar refúgio na criança, de modo que o amor dos pais à criança refere-se ao narcisismo renascido, que ganha forma de amor objetal. Nesse sentido, a deficiência interfere na formação dessa imagem e os pais não conseguem se ver no corpo da criança, encontrando dificuldade de oferecer a imagem especular para que a criança possa se identificar, comprometendo seu desenvolvimento e a formação de sua identidade.

Os termos "anormal", "monstro" (FOUCAULT, 2002), “débil", "retardado" (MANNONI, 1999), "excepcional”, "especial” (BRAUER, 1998), "pessoa portadora de deficiência" (Brasil, 2012) são substituídos pelos familiares e pessoas próximas por outros de cunho heroico, como "anjos", "eterno bebê”, "herói”, "príncipe/princesa”, para que a deficiência suplante o incômodo que ela provoca. Maesso, (1999), considera que os pais tendem a deslocar o olhar à criança para sua deficiência ou má formação, reduzindo-a em sua doença.

O sentimento de luto sustenta os primeiros meses do nascimento da criança com deficiência, em que os pais se deparam com a não realização do ideal mediante a ruptura narcísica que o corpo da criança com deficiência apresenta. Freud (1917) esclarece que o luto equivale à sensação de perda de uma pessoa ou da abstração. 
“Era Uma Vez..." Considerações Psicanalíticas Sobre A Deficiência E Os Contos De Fadas

A perda do objeto ideal não se refere à perda real, mas ao que foi perdido como objeto amoroso. A pessoa enlutada encontra resistência em substituir o objeto amoroso, uma vez que o humano tende a não renunciar às suas satisfações.

Jerusalinsky, (2007), considera que o nascimento da criança com deficiência entra em contraste com a imagem esperada pela mãe, o que pode afetar o exercício da função materna a ser desempenhada. A mãe, nesse momento, vivência em sua recusa o despertar de emoções que coloca o filho como desconhecido, invasor ou impostor, excluindo-o em comparação com a criança que não nasceu. O autor ainda reconhece que o nascimento da criança com deficiência provoca a manifestação de sentimentos de não reconhecimento, ódio e isolamento que, aliadas ao comprometimento orgânico da criança, podem indicar a estruturação de psicose ou autismo.

A deficiência pode ser compreendida a partir dos mecanismos compensatórios. É o que mostra o conto "Riquete do Topete" (PERRAULT, 1977). A narrativa apresenta a ambivalência entre beleza-estupidez e o feio-sabedoria, de modo que essas virtudes residem unicamente no mesmo personagem até o momento em que a beleza-estupidez e o feio-sabedoria se apaixonam, oferecendo sabedoria à beleza e beleza ao que era feio. Riquete era uma criança muito feia que nascera com apenas uma porção de cabelos no alto da cabeça, sendo chamado de Riquete do Topete, o primeiro nome faz referência ao que recebera da família, e o segundo é a marca de tal característica. Uma fada, que presenciou o parto, anunciou que o menino seria detentor de grande sabedoria, porém teria aspecto horroroso. Em um reino próximo, o nascimento de duas irmãs também fora presenciado pela mesma fada, que anunciou que uma delas seria bela e estúpida, e a outra feia e sábia, e à medida que o tempo passasse suas virtudes seriam proporcionalmente intensificadas.

A irmã bela frequentemente ia à floresta lamentar por seu destino. Riquete do Topete a encontrou e se mostrou solidário. A princesa the contou sobre sua incapacidade de conversar com destreza, ser interessante ou ter habilidades manuais. Riquete se propôs a desposá-la, pois ele teria a habilidade de entregar parte de sua virtude a quem ele realmente amasse, e lhe ofereceu um ano para decidir sobre o matrimônio. A princesa voltou ao reino e se tornou cada vez mais sábia. Os dois voltaram a se encontrar na data marcada, mas a princesa considerou não ter inteligência para tomar tal decisão. Riquete anunciou que ela também poderia 
transferir sua beleza para ele, tornando-o o mais belo dentre os príncipes de todos os reinos. Riquete se tornou belo e a princesa sábia, e o casamento aconteceu.

O conto mostra que a beleza como virtude exclui a capacidade de sabedoria, da mesma forma que a sabedoria porta também o feio, revelando que a aparência do corpo indica a presença ou ausência de virtudes que podem ser compensatórias ao longo da vida. Os mecanismos de compensação da debilidade física são também indicados no relacionamento da criança com deficiência, em que a mesma é mantida em seu paraíso infantil, pelos pais e educadores, mesmo quando se tornam adultos. A compensação da deficiência não equivale à manifestação de outras habilidades para a qual a criança pode se embasar para suplantar suas faltas, mas à supressão do sujeito tomado como objeto. Nesse sentido, a deficiência é compensada pela submissão ao outro.

Mannoni, (1999), menciona que o trato à criança com deficiência está embasado em aderi-la à posição de objeto de desejo, subtraindo-a da identificação como sujeito de desejo. A criança é colocada na condição de alienação, ausentandose como sujeito autônomo, o que a transforma em objeto a ser cuidado. Isso oferece subsídio ao drama da criança, ao perceber que nada se espera dela. Para a criança com deficiência não há virtude que compense a condição de estar alienado ao outro, uma vez que a submissão do sujeito como objeto configura o modo de reparar a debilidade orgânica. Os mecanismos compensatórios apontados como fantasia frente ao corpo da deficiência dizem respeito à intromissão da autoridade no corpo da criança, mantendo-a como objeto e inviabilizando a emersão do sujeito de desejo.

Em "Riquete do Topete", a convivência de virtudes antagônicas foi possível a partir da permuta entre beleza e sabedoria, reduzindo os efeitos degradantes do feio e da estupidez. Tendo o amor como recompensa da ambivalência, os personagens se pautaram na compensação de suas faltas. A discussão que se insere a partir desse conto faz referência aos mecanismos compensatórios da deficiência, os quais dizem respeito à superação da debilidade a partir da inserção da autoridade parental no corpo da criança. As figuras parentais se tornam os eternos cuidadores da criança, que mesmo em fase adulta é mantida como hóspede do universo infantil. Os mecanismos compensatórios da deficiência são identificados como os movimentos de intromissão das figuras parentais como manutenção da alienação da criança à deficiência. 
“Era Uma Vez..." Considerações Psicanalíticas Sobre A Deficiência E Os Contos De Fadas

O conto "Patinho feio" (ANDERSEN, 2013) apresenta o sofrimento do personagem frente às exclusões, xingamentos e desrespeito vivenciado no grupo devido à sua aparência destoante dos demais, e discorre sobre a imagem corporal esperada pela cultura e, consequentemente, para o sujeito. O patinho feio nasceu de um ovo muito diferente dos que estavam sendo chocados pela mãe pata no ninho, e já nesse momento indicava sua diferença em relação aos ovos das galinhas e patos comuns. A partir de seu nascimento, o patinho feio foi ultrajado pelo grupo devido sua aparência repugnante, seu modo desajeitado de andar, bater as asas e seu desafinado grasnado. Infeliz com o desprezo, patinho feio decidiu ir embora e se aventurar por diferentes e belos lugares pelo mundo. Na jornada, deparou com um grupo de cisnes que ascenderam voo do matagal. Ele também bateu suas asas e acabou reencontrando o mesmo grupo que nadava no lago. Deslumbrado com a imagem se aproximou dos cisnes, acreditando que por sua aparência repugnante seria açoitado e excluído do grupo. Porém, a imagem refletida no lago revelou que ele era tão belo quanto os admirados cisnes.

Diante da narrativa, é possível considerar, a partir de Brauer (1998), que o olhar enviesado pelo significante "deficiência" da família e da comunidade delimita o lugar da criança na cultura, indicando a presença ou ausência dos cuidados que serão a ela oferecidos. A deficiência, posta no real do corpo, tem efeito de significante localizado como marca psíquica. A deficiência, portanto, não inviabiliza a constituição psíquica, mas a antecipa, indicando a relação com a alteridade.

O corpo, conforme indica Fernandes (2011), é tomado como princípio de vida e individuação. A psicanálise, ao reconhecer o corpo como erógeno, compreende a passagem do corpo autoerótico ao corpo narcísico, fundamentado pela imersão ao campo do Outro. Nesse sentido, o corpo incide como lugar de transição do objeto e do Outro, onde nasce o sujeito que se apropria do corpo como objeto de amor do Outro, sendo constituído a partir da alteridade, ou seja, do efeito do Outro sobre o sujeito.

O corpo antecipa a imagem que o sujeito porta frente ao outro, sendo revelador do inconsciente, uma vez que a imagem conserva a substância do eu. O eu é a sensação íntima de si mesmo, cuja composição parte da fusão entre a imagem do corpo enquanto imagem mental das sensações físicas, e a imagem percebida pelo reflexo do corpo no espelho e seu poder de fascinação. O corpo é marcado, portanto, pela imagem inconsciente e pela imagem percebida no espelho. A primeira remete à 
imagem das sensações advindas do conjunto das primeiras impressões gravadas no psiquismo infantil a partir das sensações corporais no contato carnal, afetivo e simbólico com o agente materno. Na segunda, a criança reconhece que a imagem que o espelho oferece não a representa de fato, compreendendo que há uma defasagem irredutível entre a irrealidade de sua imagem e a realidade de si (NASIO, 2009).

O "Patinho feio" vivenciou o drama da exclusão, não sendo amado ou aceito pelo grupo, uma vez que sua aparência antecipou o modo pelo qual ele foi apresentado e inserido no grupo: objeto a ser expulso. A reinserção no grupo de cisnes caracterizou a forma pela qual reconheceu a imagem frente os efeitos de horror vivenciados no corpo anteriormente, permitindo a compreensão do corpo como imagem inconsciente que conserva a substância do eu. O personagem vivenciou no corpo e em sua imagem a manifestação da escória que perturba a imagem não especular do outro, resultado da exclusão do grupo familiar. A cultura incita as medidas a serem tomadas junto ao personagem que não porta a marca da herança comunitária, cujo sofrimento é vivenciado no corpo pelos açoites que incidem sobre o psiquismo através construção da imagem inconsciente do corpo, mobilizando os afetos do personagem.

A exclusão é uma marca cultural do corpo com deficiência, como pode ser percebido em momentos singulares dos personagens dos contos elencados. Neles, a ruptura com o ideal narcísico é característica que viabiliza os modos de tratamento e afastamento do personagem central. A deficiência é apresentada na sociedade como fenômeno a ser reparado, seja pela recuperação da debilidade e tentativa de padronização pela normalidade, seja pela via da inclusão enquanto supressão das barreiras sociais. Nesses modelos de inclusão, a deficiência é percebida enquanto algo que precisa receber um tratamento social, biomédico, clínico ou político, em virtude do efeito angustiante da debilidade. Os contos apresentaram, portanto, que a deficiência provoca movimentos de rejeição, mecanismos compensatórios e expulsão como tentativas para lidar com as fantasias inconscientes que emergem frente ao estranhamento do corpo.

\section{Considerações Finais}

Os contos de fadas podem desvelar dimensões humanas mobilizadoras de afetos inomináveis ou confusos. A imagem corporal dos personagens apresentados

155 Psicanálise \& Barroco em revista | v.17, n. 01 | julho de 2019 
“Era Uma Vez..." Considerações Psicanalíticas Sobre A Deficiência E Os Contos De Fadas

pelos contos "A mulher que teve a criança trocada" (GRIMM; GRIMM, 2012), "Riquete do Topete" (PERRAULT, 1977) e "Patinho feio" (ANDERSEN, 2013) está destituída da forma familiar do grupo para o qual se inserem, sendo o estranhamento, o espanto e a exclusão movimentos que sinalizam o desencontro entre o ideal e o real do corpo.

A releitura dos contos de fadas pelo viés psicanalítico, considerando o fenômeno da deficiência redimensiona a sua perspectiva, aborda os mecanismos inconscientes que persistem e se mantêm atuantes no modo de incluir a pessoa com deficiência na sociedade atual.

A aparência física ou as habilidades pessoais e sociais perpassam as expectativas e a inserção como sujeito de desejo da criança com deficiência, apontando para seus movimentos na comunidade e processo de constituição psíquica. Os contos são atemporais e manifestam as fantasias do humano, sendo possível considerar que, frente aos conteúdos encontrados nos contos, na perspectiva da deficiência, os sentimentos de isolamento, estranhamento, punição, rejeição e compensação representam os efeitos de negação do sujeito frente à diversidade de sua própria espécie. Embora as propostas políticas reconheçam a necessidade da inclusão social, há sempre resquícios da negação a esta inserção, considerando os esforços e conflitos antagônicos entre as propostas políticas em sua real representatividade e aplicação social.

A deficiência, na compreensão da psicanálise, está relacionada às condições constitutivas do sujeito, e aponta seu interesse para a sua existência independente da condição do comprometimento do corpo. O nascimento da criança com deficiência desvela projeções de seus fantasmas e a invenção de seus destinos, de modo que o corpo da deficiência mobiliza afetos relacionados ao comprometimento, dependência e debilidade, imagens negadas ao inconsciente por ferirem o ideal de perfeição narcísica, suscitando incômodo e angústia.

A construção da clínica psicanalítica da criança com deficiência apresenta, portanto, o desafio de colocar o analista em reencontro com a fantasia primitiva que assombra o campo da impossibilidade do corpo, como o medo de ser abandonado e desprezado. Trata-se de uma clínica singular, desafiadora, inundada por desconhecimentos e constantes descobertas, em constante reconhecimento do objeto que a sustenta: o investimento no sujeito. 


\section{REFERÊNCIAS}

ANDERSEN, H. C. Histórias maravilhosas de Andersen. São Paulo: Companhia das Letras, 2013.

ANDRADE, M. L. de A.; SÓLERA, M. O. A deficiência como um "espelho perturbador": uma contribuição psicanalítica à questão da inclusão de pessoas com deficiência. In:Mudanças - Psicologia da Saúde. v. 14, n.1, jan/jun, pp. 85-93, 2006. Disponível em: https://www.metodista.br/revistas/revistas-metodista/index.php/MUD/article/view/636/636. Acesso em: 25 mar. 2017, 17h45.

ARANHA, M.S.F. Integração Social do Deficiente: Análise Conceitual e Metodológica.In: Temas em Psicologia.v. 2,pp. 63-70.Ribeirão Preto, Sociedade Brasileira de Psicologia, 1995. Disponível em:http://www.adiron.com.br/arquivos/historia.pdf. Acesso em: 21 jul. 2017, $13 \mathrm{~h} 20$.

BETTELHEIM, B.A psicanálise dos contos de fadas ( $3^{\mathrm{a}}$ ed.). Trad. Arlene Caetano. Rio de Janeiro: Paz e Terra, 1979.

BRASIL, Secretaria de Direitos Humanos. Secretaria Nacional de Promoção dos Direitos da Pessoa com deficiência. Convenção sobre os Direitos das Pessoas com Deficiência: Protocolo Facultativo à Convenção sobre os Direitos das Pessoas com Deficiência: decreto legislativo $\mathrm{n}^{\mathbf{o}}$ 186, de 09 de julho de 2008: decreto $\mathrm{n}^{\mathrm{o}}$ 6.949, de 25 de agosto de 2009, $4^{\mathrm{a}}$ ed. Brasília, 2012.

BRAUER, J. F. O sujeito e a deficiência. In: Estilos da Clínica. v. 3, n.5. São Paulo, 1998. Disponível em: http://pepsic.bvsalud.org/scielo.php?script=sci arttext\&pid=S141571281998000200008 . Acesso em: 06 fev. 2017.

COELHO, N. N.O Conto de Fadas. São Paulo: Ática, 1987.

DINIZ, D.; BARBOSA, L.; SANTOS, W. R. dos. Deficiência, direitos humanos e justiça. In: Sur. Revista Internacional de Direitos Humanos.v. 6, n. 11. São Paulo, dez., 2009. Versão impressa ISSN 1806-6445. Disponível em: http://www.scielo.br/scielo.php?script=sci_arttext\&pid=S1806-64452009000200004. Acesso em: 12 fev. 2017, 8h52.

ESCOBAR, V. M. C. Um estudo sobre a função materna na constituição de sujeitos precocemente atingidos por deficiência orgânica, 2012. Dissertação (Mestrado em Psicanálise, Saúde e Sociedade) -Universidade Veiga de Almeida, Rio de Janeiro, 2012.

FERNANDES, M. H. Corpo, $4^{\mathrm{a}}$ ed. Clínica Psicanalítica. São Paulo: Casa do Psicólogo, 2011. FOUCAULT, M. Os anormais. São Paulo: Martins Fontes, 2002.

FREUD, S. À Guisa de Introdução ao Narcisismo. In. Escritos sobre a Psicologia do Inconsciente, 1914. Rio de Janeiro: Imago, 2004.

(1917). Luto e Melancolia. In. Obras Completas de Sigmund Freud. Vol. XII. Trad. Paulo César de Souza. São Paulo: Companhia das letras, pp. 193-212.

GRIMM, J.; GRIMM, W. Contos Maravilhosos Infantis e Domésticos (1812 - 1815). Trad. Christine Röhrig. v. I; II. São Paulo: CosacNaify, 2012.

JERUSALINSKY, A. et al. Psicanálise e Desenvolvimento Infantil, $4^{\mathrm{a}}$ ed. Porto Alegre: Artes e Ofícios, 2007.

LACAN, J. Escritos. Rio de Janeiro: Zahar, 1998. (Original publicado em 1966). 
MAIA, M. Novo conceito de pessoa com deficiência e proibição do retrocesso. In: Imprenta.v. 12, n. 37, p. 28 - 306, jul./set., Brasília, 2013. Advocacia-Geral da União, Centro de Estudos Victor Nunes Leal, 2002. Rede Virtual de Bibliotecas. Disponível em: http://www.lexml.gov.br/urn/urn:lex:br:rede.virtual.bibliotecas:artigo.revista:2013;100100523 6. Acesso em: 31 mar. 2017, 08h42.

MAESSO, M. C. A criança especial na psicanálise. In: Impulso: Revista de Ciências Sociais e Humanas.v.1, n.26. Piracibada, SP. Versão impressa ISSN 0103-7676, dez. 1999. pp. 139-150, 1999.

MANNONI, M. Amor, ódio, separação: o reencontro com a linguagem esquecida da infância. Trad. Vera Ribeiro. Rio de Janeiro: Jorge Zahar, 1995. . A criança retardada e a mãe. São Paulo: Martins Fontes, 1999.

NASIO, J. D. Meu corpo e suas imagens. Rio de Janeiro: Zahar, 2009.

PERRAULT, C. Contos. Lisboa: Estampa,1997.

SCHNEIDER, R. E. F.; TOROSSIAN, S. D. Contos de fadas: de sua origem à clínica contemporânea. In: Psicologia em Revista. v. 15, n. 2. Belo Horizonte, 2009. Disponível em: http://pepsic.bvsalud.org/scielo.php?script $=$ sci_arttext\&pid=S1677-11682009000200009.

Acesso em: 25 abr. 2017, 10h25. 


\title{
“Once Upon A Time...” Psychoanalytical Considerations On Disability AND FaIRY TALES
}

\begin{abstract}
Our study considers the knowledge produced by psychoanalysis about the enigmas and unconscious contents present in the fairy tales while dialogue with the concepts about the body of the deficiency. We interpret three fairy tales "The woman who had the child changed", "Riquete of Tuft" and "Ugly Duckling" in order to comprehend and describe the experience different characters who presented them in fantasies that closely pass the body of the disability. It was concluded that narratives presented rejection movements, compensatory mechanisms and expulsion to deal with the anguish and estrangement caused by body disability.
\end{abstract}

KEYWORDS: fairy tale; clinic; deficiency; childhood; psychoanalysis. 


\section{“Il ÉtTAIT UNE FOIS...” DES ConSIDÉRATIONS Psychanalytiques Sur les Contes De FÉEs Et Handicap}

\section{RÉSUMÉ}

Cette étude considère les connaissances produites par la psychanalyse sur les énigmes et les contenus inconscients présents dans les contes de fées, en dialogue avec les concepts sur le corps de la déficience. II a été lu et interprété trois contes de fées "La femme qui a fait changer l'enfant", "Riquete do Topete" et "The Ugly Duckling", racontant l'expérience des personnages avec les fantasmes qui imprègnent le corps du handicap. On en conclut que les récits présentaient des mouvements de rejet, des mécanismes de compensation et d'expulsion pour faire face à l'angoisse et à l'éloignement que le corps du handicap mobilise.

MOTS-CLÉS: contes de fées; clinique; handicapées; enfance; la psychanalyse. 
Recebido em: 27-03-2019

Aprovado em: 20-04-2019

(C) 2019 Psicanálise \& Barroco em revista

http://www.seer.unirio.br/index.php/psicanalise-barroco/index

revista@psicanaliseebarroco.pro.br

Programa de Pós-Graduação em Memória Social — UNIRIO.

Memória, Subjetividade e Criação.

http://www.memoriasocial.pro.br/proposta-area.php

161 Psicanálise \& Barroco em revista | v.17, n. 01 | julho de 2019 